\title{
The Rate Decision: Adjustable vs Fixed Rate Mortgages
}

Hossein Arsham, University of Baltimore

Deborah Ford, (E-mail: dford@ubalt.edu), University of Baltimore Joel Morse, University of Baltimore

Dennis Pitta, University of Baltimore

\begin{abstract}
Homebuyers and commercial real estate buyers who borrow funds using mortgages all must face the choice of whether to assume a fixed or an adjustable rate mortgage. Other mortgage forms with alternative characteristics are available, but the deciding question remains the same. Fixed rate mortgages never change over time, but have a high initial rate: adjustable rate, interest-only or hybrid mortgages begin with lower rates, but they change at fixed intervals over time. In contrast to professionals, consumers are often ill-equipped to understand the benefits and drawbacks of mortgage instruments. With poor product knowledge they may find the choice between fixed and variable rate mortgages overwhelming. They need help in making informed decisions. Giving the bulk of consumers the knowledge that a university level finance course conveys is not possible. Thus, there is a need for a simple applicable technique that can improve financial choice. This paper offers a straightforward forecasting model, to make the decision easier and relatively risk free. Adjustable mortgages are not always the best choice, especially in a rising interest rate market or one that has a strong possibility of rising. The model is a decision making tool that may help ordinary consumers make the best choice. Alternatively, mortgage company personnel may use the forecast to aid consumers in selecting the best mortgage.
\end{abstract}

\section{INTRODUCTION}

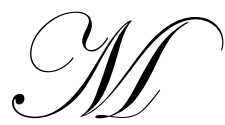

ortgage borrowers faced with the decision of a fixed or adjustable rate mortgage are often given the rule of thumb that if their horizon period is shorter than five years they should take an adjustable rate mortgage. Lengthy horizon periods necessitate a fixed rate, long term mortgage. The rationale is that adjustable rate mortgages (ARM) are cheaper in the short run, but have the potential for rising in the long run and becoming more costly than a long term mortgage. Therefore borrowers who plan to move or refinance in a relatively short time frame will never face the large rate increases. Some authors have even claimed that all borrowers, regardless of horizons, should choose adjustable rate mortgages because the early expected savings are worth the later risk. (See Longhofer).

While horizon periods are one important constraint, they are not the only determining factor of the mortgage decision. Borrowers must estimate the present value of the expected borrowing costs of each type of mortgage and choose the lowest cost. The actual present value will depend on the size of the loan, the transaction cost at the beginning, both financial and transfer costs, and the actual length of the holding period. Since ARMs have low early rates, short horizon periods are biased in their favor. However, even with short periods, ARM rates can rise

With a fixed rate mortgage, the interest rate and payment will be set for the life of the mortgage. However, for ARMs, each period may see a higher or lower rate and payment structure. These movements are not random. Indeed, interest rates have risen, fallen and started rising again in cycles over the last two decades. The complexity of the fixed versus variable rate decision process can be overwhelming to ordinary consumers (Daicon, 2004). They have low levels of financial knowledge. In their residential real estate transactions, factors such as location, 
amenities and monthly payment amounts are more important than interest rate levels and stability. Failure to make an informed choice may lead to higher costs or even result in foreclosure.

While future turning points may be difficult to identify, a forecasting model which uses past rates, can predict shorter term movements. This paper will develop a forecasting model for rates and will then compare the forecast with actual rates from 2003 to 2005. The comparison will show that if the forecast model had been used, many borrowers who assumed ARMs in the last few years would not have done so. They would have realized that the period of savings was becoming very short. The goal is to present a relatively straightforward model that can be used by even unsophisticated borrowers to help them make mortgage choices.

\section{LITERATURE REVIEW}

Until 1982, federally insured depository institutions were restricted to offering long term, fixed rate equal payment mortgages to consumers. Adjustable or variable rate mortgages (ARMs) were legalized only when volatile and rising interest rates were driving financial institutions into insolvency. The goal of the new mortgages was originally to protect lenders from interest rate risk in times of rising rates. Since the risk of rising rates is, at least partially, being transferred to borrowers, ARMs have introductory rates and payments which are less than comparable fixed rates at the time of origination.

Despite the fact that rising interest rate scenarios were the driving underlying principle of new mortgage forms, little research has been conducted on the consumer mortgage choice. Instead researchers have concentrated on such topics as the optimal refinancing strategy (Chin and Ling 1989), the determinants of prepayment (Vanderhoff, 1996), the probability of a particular mortgage being paid off in any given year (Green and Shovan, 1996), and the role of initial discounts in the pricing of ARMs (Sprecher and Willman, 2000).

Even though ARMs shift interest rate risk to consumers, the adjustable rates can solve one borrower problem if used wisely. Long term fixed rate mortgages exact high rates because future expected inflation is discounted into the current rates. As a result mortgage rates rise before income levels. As a homeowner's income rises, a fixed mortgage payment becomes a smaller percentage of gross income for the homebuyer. This phenomenon is referred to as the tilt problem (Alm, 1984). Buyers able to get into the real estate game have no problem. However, those that do not have a high enough income to cover the payments on a fixed rate mortgage either do not buy or buy a less expensive house with a smaller mortgage. They have a tilt problem because the falling payment to income ratio prevents them from buying a house at high interest rates. Since ARMs are short not long term, there is no upfront tilt problem. Rates rise over time as, presumably incomes do.

In recent years, ARMs have increasingly been used by consumers to qualify for large loans rather than to take advantage of interest rate trends. Lenders refer to ARMs and interest-only loans as 'affordability' products in the current era of relatively high home prices. In a rational, albeit uncertain, world, consumers would take out ARMs when rates were high and likely to fall. For the last few years, interest rates have been very low and, therefore, not likely to fall further. The problems of rising rates have been discussed in the popular press repeatedly. Nevertheless, in 2005, 26 percent of all home loans were interest -only and 15 percent were ARMs. Some geographic areas with high cost housing had even higher rates of non-fixed mortgages. ${ }^{1}$ Clearly these borrowers are looking for a way to solve the tilt problem. However, they are now facing interest rate risk.

\section{CONSUMER PERCEPTIONS OF RISK}

Ordinary consumers are known to have low levels of understanding about financial products and their inherent levels of financial risk (Diacon, 2004; Byrne, 2005, Martenson, 2005). Both factors are weaknesses that compound the problem that individuals face of choosing the appropriate mortgage instrument for a particular situation. Risk perceptions are important in the typical environment in which individual investors have limited information. These factors, coupled with the emotionally charged home purchase situation, make the

\footnotetext{
${ }^{1}$ New York Times, Personal Business Section, July 15,2006, “Keep Eyes Fixed on Variable Mortgages”
} 
probability for an optimum choice lower. Moreover, there are few universal metrics focusing on how risk should be conceptualized and managed. Consequently, individuals often acknowledge a degree of confusion when confronted with a prospective savings or investment decision, and have difficulty comparing the risk levels of alternative choices.

The existing literature defines perceived risk as the nature and amount of uncertainty perceived by a consumer in contemplating a particular purchase decision (Cox and Rich 1964; Grewal, Gotlieb, and Marmorstein 1994). All marketing exchanges involve some degree of uncertainty. Communications theory refers to this uncertainty as information asymmetry existing between buyers and sellers. Thus there will be some level of perceived risk for consumers for almost any purchase decision. The perceived risk varies in relation to several factors. In the consumer purchase situation, perceived risk is directly related to the importance of the product along several dimensions: cost, consumer involvement, length of usage lifetime, and overall level of domain specific knowledge (Cox 1967; Dowling and Staelin 1994, Martenson, 2005). Most consumers have a low level of specific knowledge about financial concepts and the behavior of financial instruments. Accordingly, higher priced products and products with higher involvement will invoke higher risk perceptions for consumers. In addition, product durability defined as useful life, will produce higher levels of perceived risk directly with the length of time a consumer has to live with a purchase decision. In essence, the shorter the product lifetime, the less important the impact of an incorrect choice becomes Real estate and mortgages have both high value and long usage lives and will increase the perception of risk.

There are several types of risks. However, two types of risks are relevant to the financial marketing literature (Grewal, Gotlieb, and Marmorstein 1994). Performance risk is the risk associated with uncertainties regarding the product not performing according to expected levels. Financial risk is the risk associated with the costs and expenses involved with the product, and with uncertainties about whether the product is worth that amount of money (Grewal, Gotlieb, and Marmorstein 1994). The mortgage choice presented to new home buyers involves both types of risk. Here, performance risk may be conceptualized as a mortgage not working as intended, namely not serving as an effective aid in home ownership over the length of the mortgage. Financial risk is directly pertinent to the adjustable rate mortgage metrics.

The finance literature often assumes that financial risk is objective and measured by the volatility of yields and that individuals trade-off this risk with investment return in deciding which type of mortgage to select. However, Capon et al. (1996) and MacGregor et al. (1999) found that return and risk comprise only part of the decision process for individual investors. They found that attributes other than return and risk are actively considered in personal investment decisions. Further work by Diacon and Ennew (2001) identified several different dimensions of the risk perceptions of individual consumers of financial products in the UK. They confirmed factors such as concern about the seriousness of adverse consequences, concern about the volatility of returns, and the overall poor level of consumer financial knowledge. In principle, consumers could consult with experts to help them make the best financial choice. In reality, of those consumers who do seek professional advice, there are significant differences in the expert versus lay perspective. That difference can color how consumers interpret expert advice. There is evidence which "points to serious discrepancies between consumers' recollections of discussing risk and what financial advisers say" (National Consumer Council, 2002b).

\section{FORECASTING MODEL}

Forecasting interest rates correctly, especially for long periods of time, is difficult if not impossible because the determinants of interest rates lie with monetary authorities, currency exchanges, the demand for funds and other monetary variables. However, short term forecasting of a few years is simpler. Borrowers need a relatively simple forecast model based on recent rate changes.

In this study, we use a Time-Series Model. Time-series models are particularly useful when little is known about the underlying process one is trying to forecast. The limited structure in time-series models, however, makes them reliable only in the short run. 
This type of model ignores the causes of interest rate changes and assumes future rates are dependent only on past rates. In other words, we examine the past behavior of the time series in order to infer future behavior. To model the fixed and adjustable mortgage interest rate time series, we first visually examined the graph of the series over the past three years to construct an easy to use, easy to implement model that provides a "good forecast" method. The Time-Series Model method used to produce a forecast may involve the use of a simple deterministic model such as a linear extrapolation or the use of a complex stochastic model for adaptive forecasting. To make this model easy to implement, we used the former.

Each method of time series analysis involves a different degree of model complexity and presumes a different level of comprehension about the underlying trend of the time series. The trends in the smoothed series, using the usual moving average method, indicate changes in the series to be highly nonlinear.

In order to capture the trend, one may use the Moving-Average with Trend (MAT) of order $\mathrm{n}$, where $\mathrm{n}$ is a positive odd integer number. We applied the MAT method to both time series with optimal parameter $n=3$. The MAT method uses an adaptive linearization of the trend by means of incorporating the local slopes of both the original and the smoothed time series. For technical details see Arsham (2006).

Appendices 1 and 2 present the actual data for interest rates from 2003 through 2005 obtained from The Federal Finance Housing Board web site database. The data is based on loans used to purchase single-family nonfarm homes. Only conventional non-FHA or VA insured mortgages are included. This study used effective rates, which include amortized initial charges, rather than simply contract rates,

In the tables, column two presents the effective rates; column three in each table presents the rates that would have been forecast using the MAT model; finally Column 4 presents the error or the difference between Columns two and three. The expected error should be close to $0 .^{2}$

Graphs 1 and 2, below, present plots of the actual and predicted rates using the MAT method. Clearly predicting interest rates for short periods of time is not difficult using a moving average model. ${ }^{3}$

\footnotetext{
2 The forecast error must be a random variable distributed normally with mean close to zero and constant variance across time. We have utilized a Test for Randomness JavaScript http://home.ubalt.edu/ntsbarsh/Business-stat/otherapplets/Randomness.htm, with the results indicating "little or no evidence against randomness". For testing the normality of the error term we have used the Test for Normality JavaScript http://home.ubalt.edu/ntsbarsh/Business-stat/otherapplets/Normality.htm, indication "little or no evidence against normality" For the fixed and adjustable rate the error terms are distributed normally with $($ mean $=0.008$, variance $=0.04)$, and with $($ mean $=$ 0.01 , variance $=0.04)$, respectively. The relatively small size of the variance indicates the high quality of the fit. Arsham (2006)a,b.

3 To design a Trend (MAT) method, one may use the forecasting (FC) module of WinQSB (2003) which is a commercial grade stand-alone software package.
} 
Graph $1^{4}$

Adjustable Rate Mortgages 1

Monthly National Average, 2003-2005

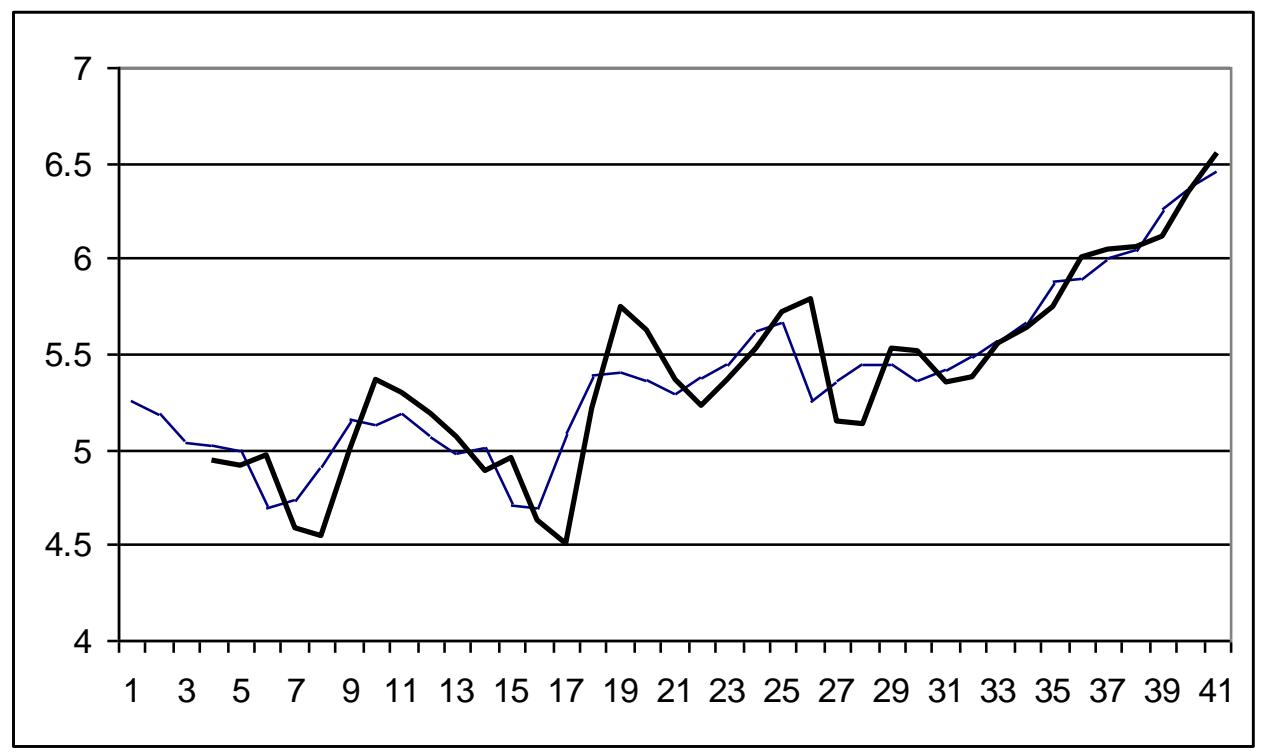

Graph 2

Fixed Rate Mortgage

Monthly National Average, 2003-2005

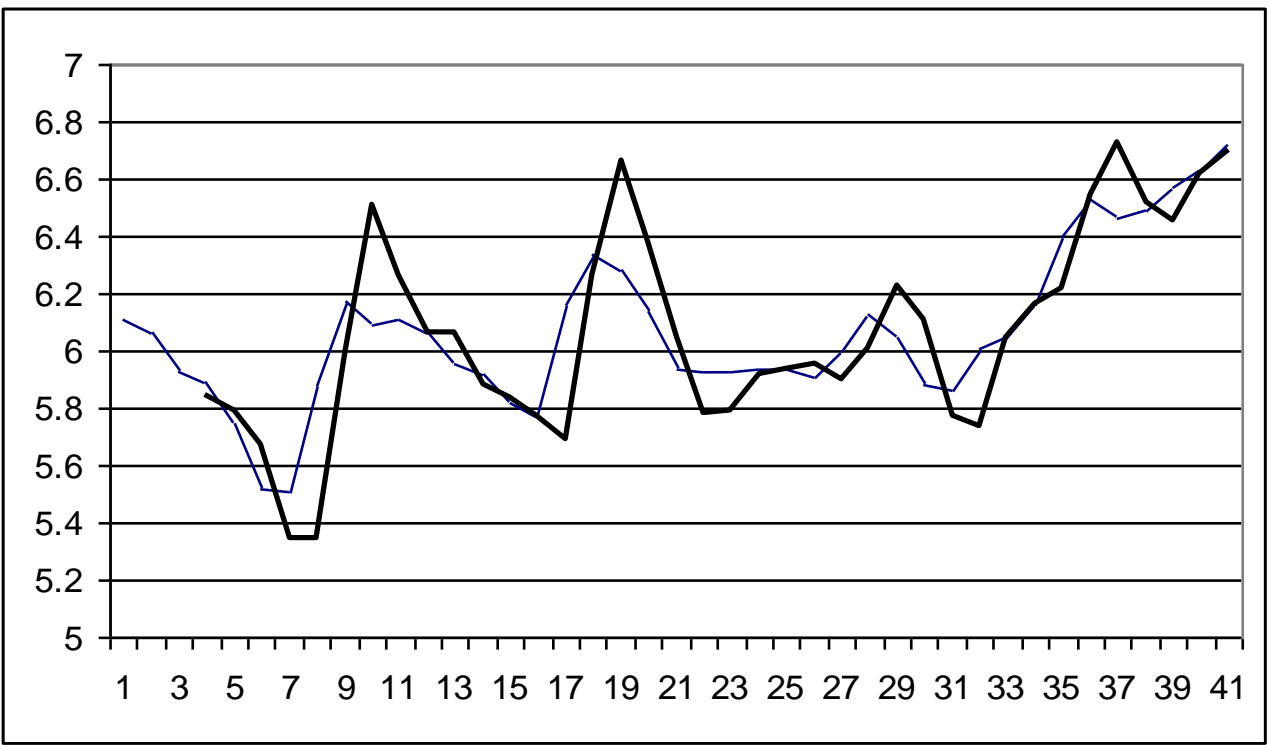

${ }^{4}$ Dark line represents the forecasted rates; thin line represents the actual rates. 
Actual adjustable and fixed rates for the first forecasted period were 6.52 and 6.79 respectively. Therefore, the absolute relative errors percentage, Arsham (2006) ${ }^{\mathrm{b}}$ are:

$100|6.52-6.56| / 6.52=0.61 \%, \quad$ and $\quad 100|6.79-6.80| / 6.79=0.15 \%$,

respectively, both small enough to conclude the forecasting method used is "good" for short-terms. Any attempt to forecast long -term, runs the danger of occurrence of turning points which are not an easy task to forecast.

\section{ADJUSTABLE VS FIXED RATES 2003-2005}

A mortgage borrower might ask of what use the above graph would have been to him if he had needed funds over this period of time. To make the ARM vs. Fixed Rate decision, the borrower must consider the present value of the savings from the lower arm rate versus the present value of the excess cost if the ARM rate rises above the fixed rate. Thus, the decision is not just about future costs, but when they occur and the appropriate discount rate to use in calculating the present value.

If a borrower chooses a fixed rate, he knows the future cost. However, if he chooses the ARM, the savings are uncertain after the initial period. Thus, he must forecast the future.

Reviewing the period 2003-2006 shows that fixed rates were relatively stable. In January of 2003, the fixed rate was 6.11 percent. By January, 2006, it was only 6.46 percent. In the same period, the ARM rate was more volatile, but had risen from 5.26 percent to 6.01. (See Appendices 1 and 2).

Graph 3 presents adjustable rates over the three year period and the set rate that a fixed rate loan would have cost in January, 2003. A borrower who had taken out a fixed rate loan in 2003 would have received a rate of $6.11 \%$. Adjustable rates did not rise above 6.11 for 3.5 years. Thus for 39 months, the borrower would have saved money by taking out an adjustable mortgage.

Graph 3

Fixed Rate, January 2003

Adjustable Rates January 2003 to May 2006

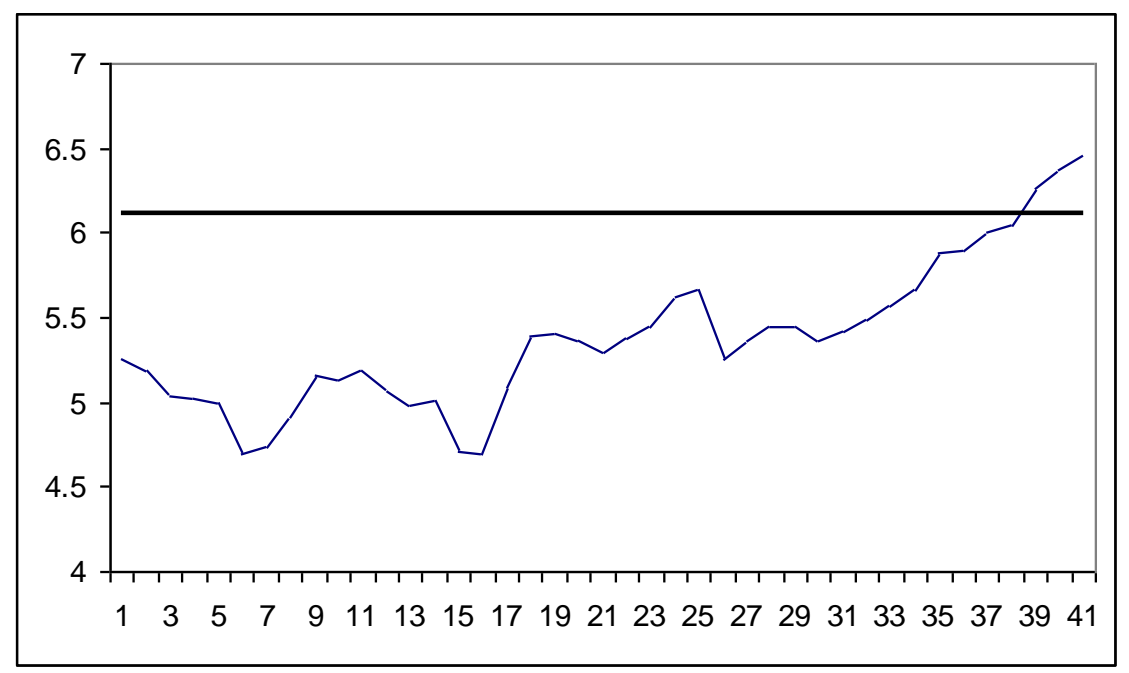


However, a borrower in January 2004 would have saved less. By January, 2004, the fixed mortgage rate had fallen slightly to 5.95 percent. The adjustable rate was 4.98 percent. The adjustable rate remained below the fixed rate for only 23 months or 2 years. This shortened period is shown in Graph 4.

Graph 4

Fixed Rate, January 2004

Adjustable Rates January 2004 to May 2006

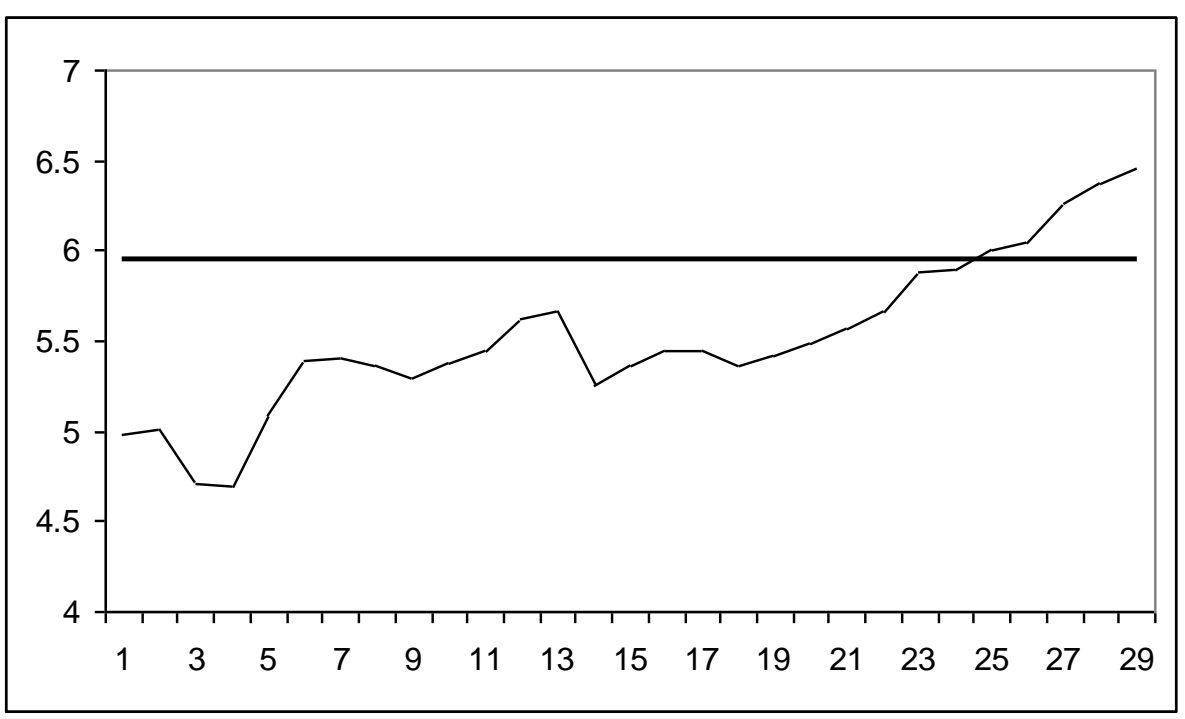

The present value of these savings would depend on the size of the loan and the discount rate. It would also depend on the refinance costs, if the borrower decided to move to a fixed rate at the time the adjustable reset. In the current cases, since fixed rates remained at or about the same level, a borrower could switch into a fixed rate that would be approximately the same as the one originally available. An alternative strategy would be to remain with the ARM and hope that rates would fall back below long term rates. However, given our forecast below, such a strategy, at this point, would be very risky.

Graphs 5 and 6 below indicate the result of assuming an ARM mortgage in January, 2005 and 2006 respectively. Increasingly the time period in which savings would occur is shorter, and, by January, 2006, the borrower would save for only four months. 
Graph 5

Fixed Rate, January 2005

Adjustable Rates January 2005 to May 2006

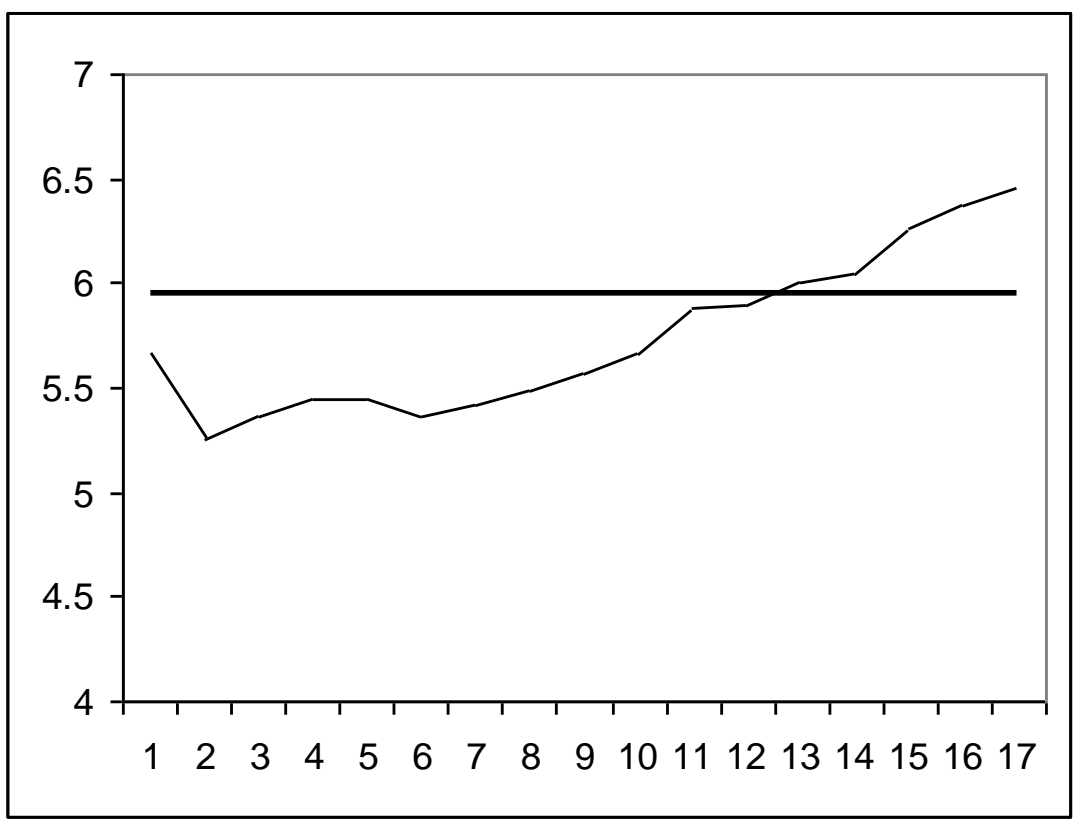

Graph 6

Fixed Rate, January 2006

Adjustable Rates January 2006 to May 2006

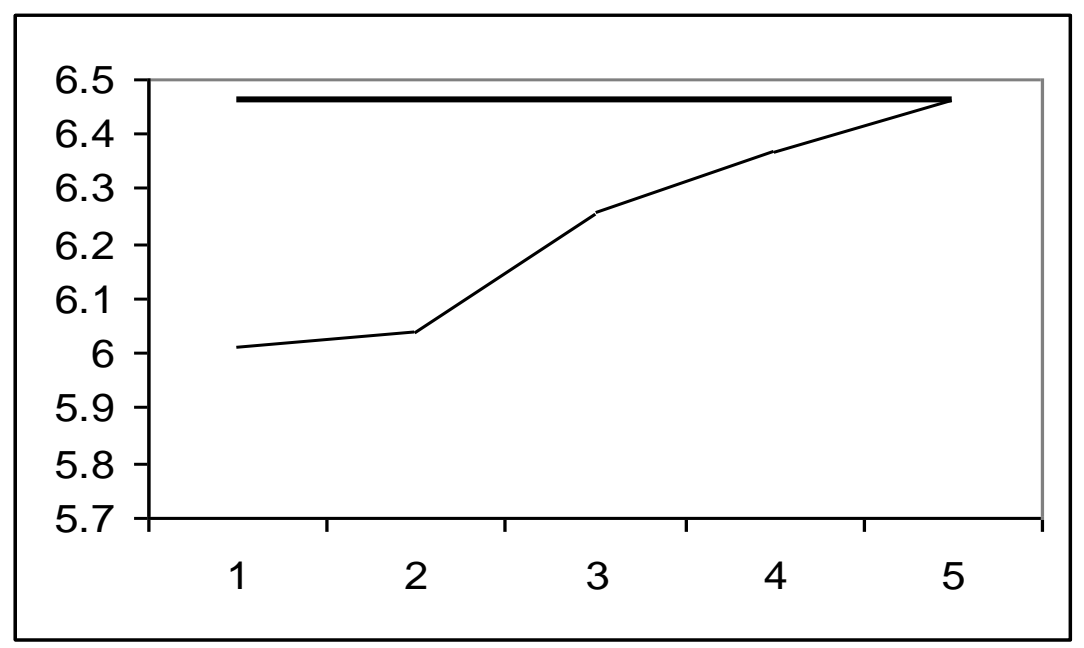




\section{FORECAST}

The prior section showed a review of the actual rates from January 2003 to May, 2006. In this time period, adjustable rate mortgages rose, and the margin between fixed rate and adjustable rate narrowed. A borrower in 2006 could have saved for a few months but no longer. The margin was very small and the savings would not have been substantial.

Using the MAT model described in Section III, the ARM rate and the fixed rate are forecast in Appendices 1 and 3. Graph 7 presents the forecast for both types of mortgages for the next three months. The fixed rate in May, 2006 was 6.73. The adjustable rate in that month was 6.46 percent. The ARM rate is forecast to rise above 6.73 in three months. Using this simple forecasting model, a borrower could easily realize that any immediate savings from the ARM would be short lived. The present value would be very small indeed.

\section{Graph 7}

Fixed Rate, May, 2006

Adjustable Rates Forecasted for June-August, 2006

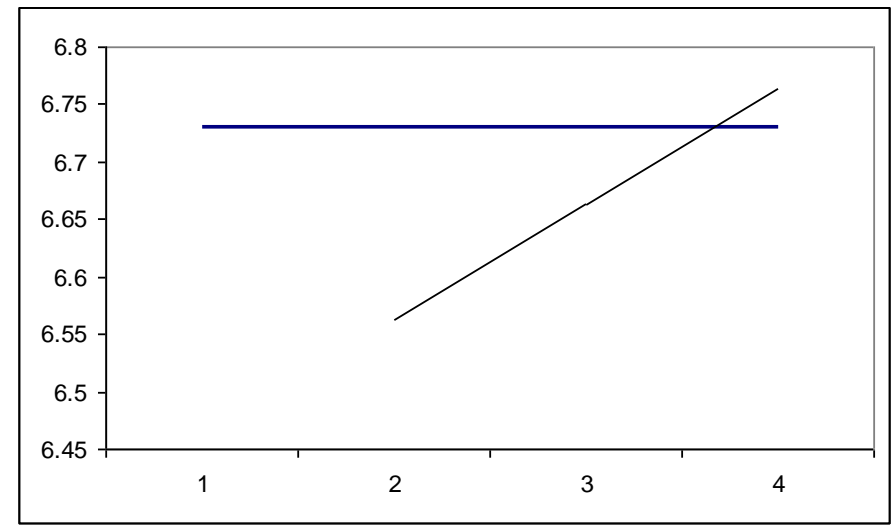

Forecast: A heavy horizontal line straight line with height Fixed 6.73

Since the actual rates for June, July, and August 2006 have now been published, the forecast for those months can be compared. As Table 1 shows, the forecast was remarkably on target. If the forecast had been based on a moving average, the error would have been even smaller. However the forecast for these months was not adjusted each month for actual results in the prior month.

Table 1

Forecast

\section{Fixed Rate}

June

July

August

Adjustable Rate

June

July

August

$\begin{array}{ll}6.80 & 6.79 \\ 6.88 & 6.90 \\ 6.96 & 6.85 \\ & \\ 6.56 & 6.52 \\ 6.66 & 6.58 \\ 6.76 & 6.72\end{array}$




\section{CONCLUSIONS}

Our short term forecasting model would allow borrowers to predict the direction of interest rates over several months. The amount of savings in that period would determine whether the choice of a fixed or adjustable term mortgage should be made. Clearly ARMs are not appropriate over all time frames, even if they do have low initial rates. Homebuyers may be able to purchase a home or purchase a more expensive home with an ARM. However, those savings may be short-lived as market rates rise.

The MAT forecasting model would appear to benefit typical individuals in selecting a residential mortgage. The technique could, in principle, be applied using a spreadsheet program and would be within the abilities of many consumers. Besides the forecasting technique the other key ingredient would be access to data which is easily available to academics and professionals and presumably would be to individuals. Mortgage company service personnel might find applying the model in a consumer interview an effective way to educate prospective customers about risks and choice. Doing so would provide a point of competitive distinction. Applying the technique would not only be instructive and educational, but might help diffuse potential consumer distress in market changes adversely affect either the fixed rate or the adjustable choice. The value in the forecast model would be to avoid that distress by making a correct informed choice.

Recent problems in the sub-prime market and with ARMs initialized with low teaser rates are not really the subject of this paper. Those mortgages were not designed to take advantage of interest rate volatility. Instead the low early rates were due to rise after a set period regardless of the market.

Since our results are based on specific historical data, one must be careful in any generalization. However, the presented methodology allows similar analyses of any time period of interest for revising decision making process. Applying this methodology to different periods of time should be the next research goal.

\section{REFERENCES}

1. Alm, James and James R. Follain (1984), Alternative Mortgage Instruments, the Tilt Problem, and Consumer Welfare, The Journal of Financial and Quantitative Analyses, Vol. 19, No.1 (March) pp113126.

2. Arsham, Hossein (2006) $)^{\mathrm{a}}$, Time Series Analysis for Business Forecasting, http://home.ubalt.edu/ntsbarsh/Business-stat/stat-data/Forecast.htm. Also the two JavaScript: Test for Randomness: http://home.ubalt.edu/ntsbarsh/Business-stat/otherapplets/Randomness.htm, and Test for Normality: http://home.ubalt.edu/ntsbarsh/Business-Stat/otherapplets/Normality.htm.

3. Arsham, Hossein (2006) ${ }^{\mathrm{b}}$, Statistical Thinking for Managerial Decisions, http://home.ubalt.edu/ntsbarsh/Business-stat/opre504.htm

4. Buist, Henry and Tyler T. Yang (2000), Housing Finance in a Stochastic Economy: Contract Pricing and Choice, Real Estate Economics, Vol 28, No1, pp117-139.

5. Byrne, Kathleen (2005), How do consumers evaluate risk in financial products? Journal of Financial Services Marketing, Vol 10, 1 pp 21-36.

6. Campbell, John Y. and Joao F. Cocco (2003), Household Risk Management and Optimal Mortgage Choice, The Quarterly Journal of Economics, (Nov) pp1449-1494.

7. Capon, N., Fitzsimons, G.J. and Prince, R.A. (1996), An individual level analysis of the mutual fund investment decision, Journal of Financial Services Research, Vol. 10 No. 1, pp. 59-82.

8. Chang Yih-Long, WinQSB: Decision Support Software for MS/OM, Version 2.0.John Wiley \& Sons, (2003). (Reasonably priced software available on-line or through the publisher).

9. Chen, Andrew H. David C. Ling (1989), Optimal Mortgage Refinancing with Stochastic Interest Rates, AREUEA Journal, Vol 17, No. 3.

10. Cox, Donald F., ed. (1967), Risk Taking and Information Handling in Consumer Behavior, Cambridge: Harvard University Press.

11. Cox, Donald F., and Stuart J. Rich (1964), Perceived Risk and Consumer Decision Making, Journal of Marketing Research, 1 (November), 32-39.

12. Diacon, Stephen, (2004), Investment risk perceptions. Do consumers and advisers agree? The International Journal of Bank Marketing, Vol. 22 No. 3, pp. 180-198. 
13. Diacon, S.R. and Ennew, C. (2001), Consumer perceptions of financial risk, Geneva Papers on Risk and Insurance: Issues and Practice, Vol. 26 No. 3, pp. 389-409.

14. Dowling, Grahame R., and Richard Staelin (1994), A Model of Perceived Risk and Intended Risk-Handling Activity, Journal of Consumer Research, 21 (June), 119-134.

15. Green, Jerry and John B. Shovan (1986), The Effects of Interest Rates on Mortgage Payments, Journal of Money, Credit, and Banking, Vol 18, No. 1 pp 41-59.

16. Grewal, Dhruv, Jerry Gotlieb, and Howard Marmorstein (1994), The Moderating Effects of Message Framing and Source Credibility on the Price-Perceived Risk Relationship, Journal of Consumer Research, 21 (June), 145-153.

17. HM Treasury (2002), Medium- and Long-Term Retail Savings in the UK: A Review, HMTreasury, London, July.

18. Longhofer, Stanley (2006), The Rate Debate, Commercial Investment Real Estate, vol 25, No 1 (Jan/Feb) pp 33-35.

19. MacGregor, D.G., Slovic, P., Berry, M. and Evensky, H.R. (1999), Perception of financial risk: a survey study of advisors and planners, Journal of Financial Planning, Vol. 12 No. 8, pp. 68-86.

20. Martenson, Rita (2005), Success in Complex Decision Contexts: The Impact of Consumer Knowledge, Involvement, and Risk Willingness on Return on Investments in Mutual Funds and Stocks. International Review of Retail, Distribution and Consumer Research, Vol 15, No. 4, pp 449-469.

21. McKensie, Joseph A. (2002), A Reconsideration of the Jumbo/Non-Jumbo Mortgage Rate Differential, Journal of Real Estate Finance and Economics Vol 25, No. 2/3 pp 197-213.

22. Sprecher, C.R. and Elliott Willman (2000), The Role of the Initial Discount in the Pricing of Adjustable Rate Mortgages, Journal of Housing Economics, Vol 9 pp 64-75.

23. VanderHoff, James (1996), Adjustable and Fixed Rate Mortgage Termination, Option Values and Local Market Conditions: An Empirical Analysis, Real Estate Economics, vol 24, no 3 pp 379-406.

\section{APPENDIX 1}

Adjustable Rate Mortgage

Monthly National Averages 2003-2005

\begin{tabular}{|c|c|c|c|c|c|c|c|}
\hline Month & Actual & Forecast & Error & Month & Actual & Forecast & Error \\
\hline 1 & 5.26 & & & 25 & 5.66 & 5.72 & -0.06 \\
\hline 2 & 5.19 & & & 26 & 5.26 & 5.79 & -0.53 \\
\hline 3 & 5.04 & & & 27 & 5.36 & 5.15 & 0.21 \\
\hline 4 & 5.02 & 4.94 & 0.08 & 28 & 5.44 & 5.13 & 0.31 \\
\hline 5 & 4.99 & 4.91 & 0.08 & 29 & 5.45 & 5.53 & -0.08 \\
\hline 6 & 4.7 & 4.97 & -0.27 & 30 & 5.37 & 5.51 & -0.14 \\
\hline 7 & 4.73 & 4.58 & 0.15 & 31 & 5.42 & 5.35 & 0.07 \\
\hline 8 & 4.91 & 4.55 & 0.36 & 32 & 5.49 & 5.38 & 0.11 \\
\hline 9 & 5.16 & 4.99 & 0.17 & 33 & 5.57 & 5.55 & 0.02 \\
\hline 10 & 5.13 & 5.36 & -0.23 & 34 & 5.66 & 5.64 & 0.02 \\
\hline 11 & 5.18 & 5.29 & -0.11 & 35 & 5.88 & 5.74 & 0.14 \\
\hline 12 & 5.07 & 5.18 & -0.11 & 36 & 5.9 & 6.01 & -0.11 \\
\hline 13 & 4.98 & 5.07 & -0.09 & 37 & 6.01 & 6.05 & -0.04 \\
\hline 14 & 5.01 & 4.88 & 0.13 & 38 & 6.04 & 6.06 & -0.02 \\
\hline 15 & 4.71 & 4.96 & -0.25 & 39 & 6.26 & 6.12 & 0.14 \\
\hline 16 & 4.70 & 4.63 & 0.07 & 40 & 6.37 & 6.35 & 0.02 \\
\hline 17 & 5.09 & 4.50 & 0.59 & 41 & 6.46 & 6.55 & -0.09 \\
\hline 18 & 5.39 & 5.21 & 0.18 & & & & \\
\hline 19 & 5.41 & 5.75 & -0.34 & & & & \\
\hline 20 & 5.36 & 5.62 & -0.26 & & & & \\
\hline 21 & 5.29 & 5.36 & -0.07 & & & 3-Steps & Forecast \\
\hline 22 & 5.38 & 5.23 & 0.15 & & & 1 & 6.56 \\
\hline 23 & 5.45 & 5.36 & 0.09 & & & 2 & 6.66 \\
\hline 24 & 5.62 & 5.53 & 0.09 & & & 3 & 6.76 \\
\hline
\end{tabular}

Source; Federal Housing Finance Board, Monthly Interest Rate Series (MIRS) 


\section{APPENDIX 2}

Fixed Rate Mortgage

Monthly National Average, 2003-2006

\begin{tabular}{|c|c|c|c|c|c|c|c|}
\hline Month & Actual & Forecast & Error & Month & Actual & Forecast & Error \\
\hline 1 & 6.11 & & & 25 & 5.94 & 5.94 & -0.00 \\
\hline 2 & 6.06 & & & 26 & 5.91 & 5.95 & -0.04 \\
\hline 3 & 5.93 & & & 27 & 6.00 & 5.90 & 0.1 \\
\hline 4 & 5.89 & 5.85 & 0.04 & 28 & 6.13 & 6.01 & 0.12 \\
\hline 5 & 5.75 & 5.79 & -0.04 & 29 & 6.05 & 6.23 & -0.18 \\
\hline 6 & 5.52 & 5.67 & -0.16 & 30 & 5.88 & 6.11 & -0.23 \\
\hline 7 & 5.51 & 5.35 & 0.16 & 31 & 5.86 & 5.77 & 0.09 \\
\hline 8 & 5.88 & 5.35 & 0.53 & 32 & 6.01 & 5.74 & 0.27 \\
\hline 9 & 6.17 & 6.00 & 0.17 & 33 & 6.05 & 6.05 & 0 \\
\hline 10 & 6.09 & 6.51 & -0.42 & 34 & 6.16 & 6.16 & 0 \\
\hline 11 & 6.11 & 6.26 & -0.15 & 35 & 6.40 & 6.22 & 0.18 \\
\hline 12 & 6.06 & 6.06 & 0 & 36 & 6.53 & 6.55 & -0.02 \\
\hline 13 & 5.95 & 6.06 & -0.11 & 37 & 6.46 & 6.73 & -0.27 \\
\hline 14 & 5.92 & 5.88 & 0.04 & 38 & 6.49 & 6.52 & -0.03 \\
\hline 15 & 5.82 & 5.84 & -0.02 & 39 & 6.57 & 6.45 & 0.12 \\
\hline 16 & 5.77 & 5.77 & 0.003 & 40 & 6.63 & 6.62 & 0.01 \\
\hline 17 & 6.16 & 5.69 & 0.47 & 42 & 6.73 & 6.70 & 0.03 \\
\hline 18 & 6.34 & 6.26 & 0.08 & & & & \\
\hline 19 & 6.28 & 6.66 & -0.38 & & & & \\
\hline 20 & 6.14 & 6.38 & -0.24 & & & & \\
\hline 21 & 5.94 & 6.05 & -0.11 & & & 3-Steps & Forecasts \\
\hline 22 & 5.93 & 5.78 & 0.15 & & & 1 & 6.80 \\
\hline 23 & 5.93 & 5.79 & 0.14 & & & 2 & 6.88 \\
\hline 24 & 5.94 & 5.92 & 0.02 & & & 3 & 6.96 \\
\hline
\end{tabular}

Source; Federal Housing Finance Board, Monthly Interest Rate Series (MIRS) 